\title{
Improving the health of homeless youth through community-based sexual health promotion
}

\author{
Nikki K Woods*, Andrea Black, Danika Burton, Hauna Payne and Megan Robertson \\ Department of Public Health Sciences, Wichita State University, 1845 Fairmount, Box 43, Wichita, USA
}

\begin{abstract}
Background: Although sexually transmitted infections (STIs) impact individuals of all ages, adolescents and those who are homeless, are at a particularly increased risk. The Centres for Disease Control and Prevention (CDC) estimated adolescents aged 15-24 years account for half of all new STIs in the US. Homeless youth are generally knowledgeable about transmission, prevention, and treatment of STIs, however, there are disparities regarding access and knowledge of free preventive and medical services. This pilot study explored the knowledge, attitudes and behaviours of homeless youth before and after the implementation of a sexual health education program.

Methods: The curriculum included four separate topic presentations in small group sessions of 7-15 participants at local community-based street outreach program related to reproductive anatomy, STIs, contraception, and an interactive reproductive physical exam simulation. This study used a retrospective pre/post survey to evaluate the impact.

Results: Fifteen individuals participated in at least one of the sessions. Participants who attended 3-4 of the sessions showed greater knowledge improvement than those who only attended 1-2 sessions. Basic knowledge was the same (e.g., will visit a medical care provider when needed, 100\% both groups) but more advanced knowledge was greater for those who attended 3-4 sessions (Plan B usage, 43\% ( $n=3 / 7)$ vs. $75 \%(n=3 / 4)$ ).
\end{abstract}

Conclusion: By overcoming barriers regarding health disparities through education and collaboration, this study was able to empower at-risk youth to be proactive in their own sexual health.

\section{Introduction}

Although sexually transmitted infections (STIs) impact individuals of all ages, adolescents and those who are homeless, are at a particularly increased risk. According to the Centres for Disease Control and Prevention (CDC), there are 20 million new cases of STIs each year in the United States. About half of these infections are in people between the ages of 15 and 24 . This age group only accounts for about $25 \%$ of the sexually active population yet has a higher rate of STIs than other age categories [1].

Homeless youth are generally knowledgeable about transmission, prevention, and treatment of STIs, however, there are disparities regarding access and knowledge of free preventive and medical services [2-4]. A previous study by Rew et al. [4], reported homeless youth wanted to know about free medical services, birth control, free STI testing, where to go for treatment and testing, and information about Planned Parenthood services (a local non-profit organization that provides sexual health care in the United States and globally). Homeless youth in this study reported high levels of knowledge about transmission, prevention, and treatment of STIs. Although, they reported the need for more specific information about condom use and availability of free condoms (all youth) and more information on pregnancy prevention (female participants). Additionally, homeless youth reported they have barriers to seeking diagnosis and treatment for STIs including cost and not knowing where to go [4].

This study was based on existing gaps in the literature related to homeless youth and sexual health education. This pilot study explored the knowledge, attitudes and behaviours of homeless youth after the implementation of a sexual health education program based on previously reported gaps in health education for this population. The goal was to further understand how STI and sexual health education impacted the behaviours of homeless young adults.

\section{Methods}

\section{Study design and sample}

This research was an exploratory, pilot study using retrospective pre and post surveys that employed a group-based sexual health education program with a convenience sample from a local street outreach program. The first three sessions were held at the homeless youth shelter, and the fourth session was held at a clinical training facility that included medical examination rooms.

\section{Curriculum}

Using existing, evidence-based literature, our team created a fourpart curriculum to be presented in small group sessions. The team included a doctoral trained behavioural psychologist, a social worker, and three physician assistant students. The curriculum included four

${ }^{\star}$ Correspondence to: Nikki Keene Woods, Department of Public Health Sciences, Wichita State University, 1845 Fairmount, Box 43, Wichita, USA, Tel: 316-978-3060; E-mail: Nikki.keenewoods@wichita.edu

Key words: homeless youth, sexual health, disparities, STIs, health education

Received: August 12, 2019; Accepted: August 26, 2019; Published: August 29, 2019 
separate topic presentations: (1) Reproductive anatomy [5,6], (2) Sexually transmitted infections (STIs) [7-11], (3) Contraception and STI prevention [12-18], and (4) Medical examination simulation [1921]. Each session included a handout on the topic, a brief presentation, and a period of questions and answers in a small group setting.

\section{Participants}

Homeless youth were invited to participate in the sexual health educational sessions by staff members. The group size ranged from 7-15 participants over the course of the project. Upon completion of the final group session, participants received a t-shirt as an incentive for participation. Participants also received $\$ 5$ gift cards as incentives for participating in group sessions.

\section{Data collection and analysis}

A short retrospective pre-post questionnaire was administered to each participant after the last session. The purpose of the questionnaire was to survey participants in order to provide demographic data and compare their knowledge prior to and after the sexual health education sessions about reproductive anatomy, sexually transmitted infections (STIs), contraception, and an interactive reproductive physical exam simulation. Four demographic questions were included, and 17 attitude, knowledge and behaviour questions were included. The survey was modified from a previous sexual health curriculum evaluation tool [17]. Data were analysed using descriptive statistics. The study was ethically approved by a University Institutional Review Board.

\section{Results}

Overall, 15 individuals participated in at least one of the sessions and 12 participants responded to the survey at the final group education session. The number of participants fluctuated from 7-15 individuals at each session. The majority were female $(70 \%, n=7)$, average age 20.3 years $(S D=1.58)$, and $80 \%$ were Caucasian $(n=8)$ while $20 \%$ were Hispanic/Latino $(n=2)$. All participants were English speaking. Almost half of participants had completed some high school $(44 \% n=4)$, an equal percentage completed high school $(44 \%, \mathrm{n}=4)$ and one individual had completed college.

Participants who attended three or four of the sessions showed greater knowledge improvement than those who only attended only one or two sessions (Table 1). Basic knowledge was the same (e.g., will visit a medical care provider when needed, $100 \%$ both groups) but more advanced knowledge was greater for those who attended three or four sessions (Plan B usage, $43 \%(n=3 / 7)$ vs. $75 \%(n=3 / 4)$ ). Participants who attended more sessions had better sexual health attitudes (questions one through four), better behavioural intentions (three of four questions had higher ratings), and higher knowledge (four of six questions had higher ratings). However, participants who attended more sessions reported a lower self-efficacy in relation to sexual health topics by rating higher on only one of the three self-efficacy questions (Table 1).

\section{Discussion}

This pilot study examined the knowledge, attitudes and behaviours of homeless youth before and after the implementation of a sexual health educational program. Our primary goal was to educate atrisk homeless youth about STIs. The secondary goal was to provide information about accessing resources and services that are available in the community. For example, free or low cost STI testing/treatment and birth control methods. Homeless young adults are more likely
Table 1. Post-survey question results $(\mathrm{N}=12)$

\begin{tabular}{|c|c|c|}
\hline Question & $\begin{array}{l}\text { Sessions } \\
1 \text { or } 2\end{array}$ & 3 or 4 \\
\hline & $\mathrm{n}=7$ & $\mathrm{n}=4$ \\
\hline \multicolumn{3}{|l|}{ Attitudes } \\
\hline 1. Getting a STI is a big deal & $43 \%$ & $75 \%$ \\
\hline $\begin{array}{l}\text { 2. Young people who have had sex should get tested for } \\
\text { STIs. }\end{array}$ & $88 \%$ & $100 \%$ \\
\hline $\begin{array}{l}\text { 3. If used correctly ever time, condoms can prevent HIV and } \\
\text { other STIs }\end{array}$ & $34 \%$ & $50 \%$ \\
\hline 4. Using contraceptives can lower the chance of pregnancy & $75 \%$ & $75 \%$ \\
\hline \multicolumn{3}{|l|}{ Behavioral Intentions } \\
\hline $\begin{array}{l}\text { 5. I understand how to protect myself from AIDS or other } \\
\text { STIs. }\end{array}$ & $88 \%$ & $100 \%$ \\
\hline $\begin{array}{l}\text { 6. I don't want to be pregnant (or get someone pregnant) } \\
\text { right now. }\end{array}$ & $63 \%$ & $50 \%$ \\
\hline 7. I plan to visit a doctor if I have signs of a STI. & $100 \%$ & $100 \%$ \\
\hline $\begin{array}{l}\text { 8. I would get a pap smear (or male genital exam), even if I } \\
\text { am not having sex to make sure I am healthy. }\end{array}$ & $50 \%$ & $100 \%$ \\
\hline \multicolumn{3}{|l|}{ Self-Efficacy } \\
\hline 9. If I decide to have sex, I will use a condom every time. & $63 \%$ & $50 \%$ \\
\hline $\begin{array}{l}\text { 10. I know where to find help in my community if I need to } \\
\text { see a doctor. }\end{array}$ & $88 \%$ & $75 \%$ \\
\hline $\begin{array}{l}\text { 11. I know where to find a free condom if I need one in the } \\
\text { future. }\end{array}$ & $88 \%$ & $100 \%$ \\
\hline \multicolumn{3}{|l|}{ Knowledge } \\
\hline $\begin{array}{l}\text { 12. I can't get pregnant (or get someone pregnant) having sex } \\
\text { for the first time. }\end{array}$ & $63 \%$ & $75 \%$ \\
\hline $\begin{array}{l}\text { 13. You cannot tell if someone has an STI just by looking at } \\
\text { them. }\end{array}$ & $50 \%$ & $33 \%$ \\
\hline 14. STIs can result in infertility. & $86 \%$ & $75 \%$ \\
\hline $\begin{array}{l}\text { 15. Emergency contraceptive pills (Plan B or the "morning } \\
\text { after pill") can be taken up to } 5 \text { days after having } \\
\text { unprotected vaginal sex to reduce the risk of pregnancy. }\end{array}$ & $43 \%$ & $75 \%$ \\
\hline $\begin{array}{l}\text { 16. I understand my body, especially my private } \\
\text { (reproductive) parts. }\end{array}$ & $88 \%$ & $100 \%$ \\
\hline 17. Painful urination is a common STI symptom. & $50 \%$ & $75 \%$ \\
\hline
\end{tabular}

to be sexually active, have multiple partners, engage in sex work, and report low rates of condom usage [2-4]. Preventing STIs can improve their long-term health. Results showed that participants in attendance for at least half of the sessions showed greater improvements in sexual health attitudes, behavioural intentions and sexual health knowledge. However, participants who attended more sessions reported a lower self-efficacy in relation to sexual health topics based on the survey responses. This could be based on the relationships formed between the health educators and participants during the group sessions and reflect an honest, but more vulnerable survey response. The vulnerable type of response would require a trusting relationship between participant and researchers.

While this pilot study had many strengths, it was not without limitations. Due to the nature of the organization and homeless status of participants, the participants in the group sessions were not always consistent from week to week. The participants also had varying levels of education and background that may have influenced their ability to understand some of the topics. The health education curriculum was broad and could be improved through tailoring it to specifically homeless male youth to increase the relevancy. The goal of the pilot study was to provide education and resources to fill a community need, but the four-part curriculum barely scratched the surface, as expanded programs are needed to meet the needs of the population. Additionally, the retrospective pre-post survey design was not effective for this population. Many participants seemed confused by the questions, 
as it asked for participants to report their knowledge, attitudes, and beliefs before the program started, at the end of the program. Splitting these ratings up and specifically giving them before the first session and again after the second session might avoiding confusion among the participants and reduce biases. The survey questions could also be improved through continued piloting for understandability.

This pilot study explored the need for more knowledge related to sexual health and available resources for homeless youth including the development of an educational curriculum focused on improving sexual health behaviours, attitudes and beliefs, as well as promoting overall well-being for this population. While many homeless youth's are generally knowledgeable about the transmission, prevention, and treatment of STIs, they commonly lack access to community resources. This health education program was able to address this gap in knowledge by bringing awareness of those community resources and strategies to access those resources as part of the curriculum.

\section{Conclusion}

This community-based sexual health education program could be used in similar settings to improve behaviours and promote sexual health knowledge for homeless youth, with an overarching goal to improve health outcomes for this vulnerable population. By overcoming barriers regarding health disparities through education and collaboration, this study was able to empower at-risk youth to be proactive in their own sexual health.

\section{References}

1. Diseases \& Conditions. Available from: https://www.cdc.gov/diseasesconditions/ index.html

2. Boyer CB, Greenberg L, Chutuape K, Walker B, Monte D, et al. (2016) Exchange of Sex for Drugs or Money in Adolescents and Young Adults: An Examination of Sociodemographic Factors, HIV-Related Risk, and Community Context. J Community Health 42: 90-100. [Crossref]

3. Gerassi L, Jonson-Reid M, Drake B (2015) Sexually Transmitted Infections in a Sample of At-Risk Youth: Roles of Mental Health and Trauma Histories. $J$ Child Adolesc Trauma 9: 209-216. [Crossref]
4. Rew L, Chambers KB, Kulkarni S (2002) Planning a sexual health promotion intervention with homeless adolescents. Nurs Res 51: 168-174. [Crossref]

5. Male Reproductive System. Available from: https://kidshealth.org/en/teens/male-repro. html?WT.ac=ctg\#catchanging-body

6. Female Reproductive System. Available from: https://kidshealth.org/en/teens/femalerepro.html?WT.ac=ctg\#catchanging-body

7. American Sexual Health Accociation. Available from: http://www.ashasexualhealth.org

8. Hepatitis B medication. Available from: https://www.generichepatitiscdrugs.com/ buying-generic-hepatitis-b-medicine.

9. Medscape. Available from: https://www.medscape.com

10. Sexual Health. Available from: https://teenshealth.org/en/teens/sexualhealth/\#catcontraception

11. What Does Herpes Look Like - Pictures of STDs. Available from: https://www. thestdproject.com/pictures-of-stds-what-does-herpes-look-like

12. Rights, Respect, Responsibility. Available from: https://3rs.org/3rs-curriculum/3rscurric-search

13. Birth Control. Available from: https://www.plannedparenthood.org/learn/birthcontrol

14. Birth Control. Available from: https://stayteen.org/sex-ed/birth-control-explorer

15. Reproduction, Day 5: Birth Control. Available from: https://www.kingcounty.gov/ depts/health/locations/family-planning/education/FLASH/ /media/depts/health/ family-planning/documents/special-education/SpecialEducationLesson23.ashx

16. Birth Control Methods. Available from: https://www.optionsforsexualhealth.org/facts/ birth-control/methods

17. Realini JP, Buzi, RS, Smith PB, Martinez M (2010) Evaluation of "big decisions": an abstinence-plus sexuality curriculum. $J$ Sex Marital Ther 36: 313-326. [Crossref]

18. Testicular cancer society. Available from: https://testicularcancersociety.org/

19. Genital Examination. Available from: https://www.mentalhelp.net/sexuality/std examination

20. Women's Health Care Physicians. Available from: https://www.acog.org/

21. Bickley LS, Szilagyi PG (2009) Bates guide to physical examination and history taking Philadelphia: Wolters Kluwer, pp: 508-533.

Copyright: $\odot 2019$ Woods NK. This is an open-access article distributed under the terms of the Creative Commons Attribution License, which permits unrestricted use, distribution, and reproduction in any medium, provided the original author and source are credited. 